\title{
Society for palliative radiation oncology: report from the Sixth Annual Meeting [2019]
}

\author{
Emily Martin ${ }^{1}$, Yolanda Tseng ${ }^{2}$, Charles B. Simone II $^{3}$, Candice Johnstone ${ }^{4}$ \\ ${ }^{1}$ Department of Medicine, University of California, Los Angeles, CA, USA; ${ }^{2}$ Department of Radiation Oncology, University of Washington, Seattle, \\ WA, USA; ${ }^{3}$ Department of Radiation Oncology, New York Proton Center, New York, NY, USA; ${ }^{4}$ Department of Radiation Oncology, Medical \\ College of Wisconsin, Milwaukee, WI, USA \\ Correspondence to: Candice Johnstone, MD, MPH. Department of Radiation Oncology, Medical College of Wisconsin, Milwaukee, WI, USA. \\ Email: cjohnstone@mcw.edu.
}

\begin{abstract}
The Society for Palliative Radiation Oncology (SPRO) is an international professional group dedicated to advancing the field of palliative radiation oncology by promoting evidence-based palliative radiotherapy and excellence in primary palliative care through research, education, collaboration, and patient advocacy. SPRO held its 6th Annual Meeting in Chicago, IL, USA on September 15th, 2019. The goals from SPRO's 5th Annual Meeting and progress towards those goals were reviewed, new research and educational opportunities were discussed, short- and long-term goals for the Society were detailed, and research and lifetime achievement awards were bestowed. This Meeting Report summarizes the proceedings of the 6th Annual Meeting and described future directions for SPRO.
\end{abstract}

Keywords: Society for Palliative Radiation Oncology (SPRO); 6th Annual Meeting; palliative radiation oncology

Submitted Feb 10, 2020. Accepted for publication Apr 20, 2020.

doi: $10.21037 /$ apm-20-361

View this article at: http://dx.doi.org/10.21037/apm-20-361

The Society for Palliative Radiation Oncology (SPRO) is an international professional group dedicated to advancing the field of palliative radiation oncology by promoting evidence-based palliative radiotherapy and excellence in primary palliative care through research, education, collaboration, and patient advocacy (1). SPRO held its 6th Annual Meeting in Chicago, IL, USA on September $15^{\text {th }}$, 2019 (Table 1, Figures 1-4).

Dr. Candice Johnstone, Co-Chair of the Annals of Palliative Medicine Palliative Radiotherapy Subcommittee, started the meeting with a warm welcome and facilitated introductions among the 38 physicians and trainees in attendance. She summarized the goals from last year's Annual Meeting (2) and highlighted the Society's success in working towards those goals, including establishing non-profit status and formalizing its organizational structure. Dr. Emily Martin provided an update regarding the SPRO website and highlighted new opportunities to be involved in the SPRO committees. Dr. Joshua Jones next presented SPRO's many accomplishments over the past six years, including efforts to formalize palliative radiotherapy curricula in residency training, to incorporate patient reported outcomes into radiation oncology clinical practices, and to develop new palliative radiotherapy programs at institutions across the United States. Dr. Jones also listed the numerous publications that have resulted from the research of SPRO members. Dr. Charles Simone next commented on the tremendous success of the Annals of Palliative Medicine, the Society's official peer-reviewed journal, which has doubled in readership each year for the past several years and earned its first official impact factor in June 2019 (3). Dr. Simone also encouraged SPRO members to submit original research and review manuscripts to the Annals of Palliative Medicine.

During a break-out session, SPRO members brainstormed both short- and long-term goals for the Society. The proposed goals included: increasing access to palliative care education; establishing best practices for coordinating care and communicating with neurosurgery teams; developing a formal mentorship program; forging 
Table 1 Agenda

\begin{tabular}{ll}
\hline Agenda item & Speaker/facilitator \\
\hline Welcome and introductions & Candice Johnstone \\
Summary of SPRO's efforts and achievements over the past year & \\
Updates pertaining to the SPRO website & Emily Martin \\
$\begin{array}{l}\text { Discussion of the society's committees and upcoming opportunities for involvement } \\
\text { Summary of SPRO's accomplishments and members' publications over the past } \\
\text { six years }\end{array}$ & Joshua Jones \\
$\begin{array}{l}\text { Acknowledgement of the success of the Annals of Palliative Medicine, the society's } \\
\text { official peer-reviewed journal }\end{array}$ & Charles Simone \\
$\begin{array}{l}\text { Breakout sessions } \\
\text { Dinner and networking }\end{array}$ & Tracy Balboni, Timur Mitin, Yolanda Tseng, Emily \\
Rising Star Award & Martin, Joshua Jones, Candice Johnstone \\
Lifetime Achievement Award & \\
Concluding remarks & Presenter: Christen Elledge; recipient: Sara Alcorn \\
\hline
\end{tabular}

SPRO, Society for Palliative Radiation Oncology.

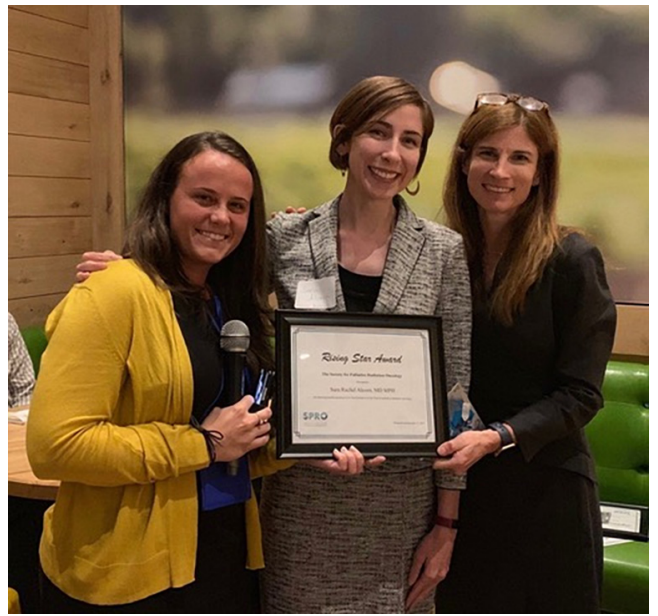

Figure 1 Dr. Alcorn received the 2019 Rising Star Award. Dr. Christen Ellege (nominator), Dr. Sara Alcon (award recipient) and Dr. Tracy Balboni (Chair, awards committee) pictured.

relationships with other professional organizations (e.g., the American Academy of Hospice and Palliative Medicine; the European Association for Palliative Care; the Canadian Palliative Radiation Oncology Group); assisting in the establishment of more palliative radiation oncology services; and expanding interest in palliative care among medical students and residents. The group proposed several possible

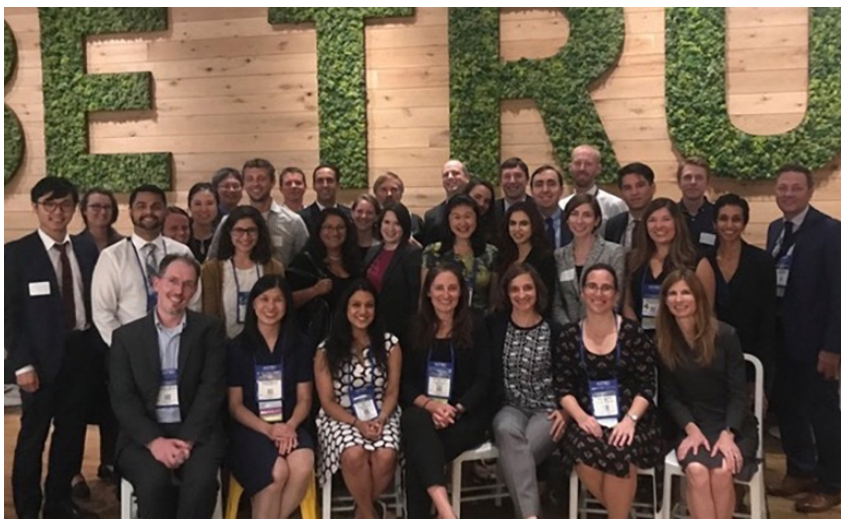

Figure 2 Attendees at the SPRO annual meeting. SPRO, Society for Palliative Radiation Oncology.

research projects and expressed interest in forming a centralized way to collaborate on research moving forward. The three top priorities for 2020 are to formalize the Society's non-profit status, to establish membership for SPRO committees, and to begin work on an educational curriculum in palliative radiation oncology.

During the meeting, two SPRO awards were presented: the Rising Star Award and the Lifetime Achievement Award. Dr. Christen Elledge presented the Rising Star Award to the awardee, Dr. Sara Alcorn, Assistant Professor 


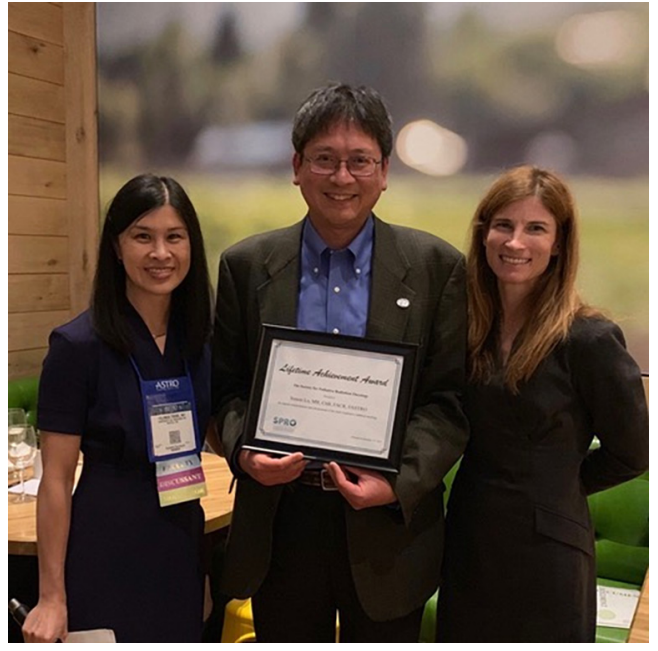

Figure 3 Dr. Simon Lo received the 2019 Lifetime Achievement Award. Dr. Yolanda Tseng (nominator), Dr. Simon Lo (recipient) and Dr. Tracy Babloni (chair, awards committee).

in the Department of Radiation Oncology at the Johns Hopkins School of Medicine. Dr. Elledge highlighted Dr. Alcorn's commitment to the field of palliative radiation oncology and her significant contributions to palliative radiation oncology research. As a medical student at Harvard Medical School, Dr. Alcorn sought out the mentorship of Dr. Tracy Balboni and published her first papers examining the spiritual and religious needs of patients with advanced cancer. As a resident, she created and maintained a retrospective database of $>700$ patients treated with palliative radiotherapy at The Johns Hopkins Hospital. Using this database, she was able to publish multiple papers, including an analysis of patterns of care among patients receiving palliative radiotherapy for bone metastases and an analysis of palliative radiotherapy practice patterns among pediatric oncology patients. During residency and as part of her doctoral thesis for her $\mathrm{PhD}$, Dr. Alcorn worked to develop a random survival forests model to predict survival in patients with metastatic cancer referred for palliative radiotherapy.

Dr. Yolanda Tseng then presented the Lifetime Achievement Award to Dr. Simon Lo, Professor of Radiation Oncology at the University of Washington. Dr. Lo is an internationally recognized expert in management of brain and bone metastases and is focused on disseminating best practices in radiotherapeutic management of metastatic disease. He has authored over 200 peer-reviewed original articles, reviews, and letters. He a member of the American

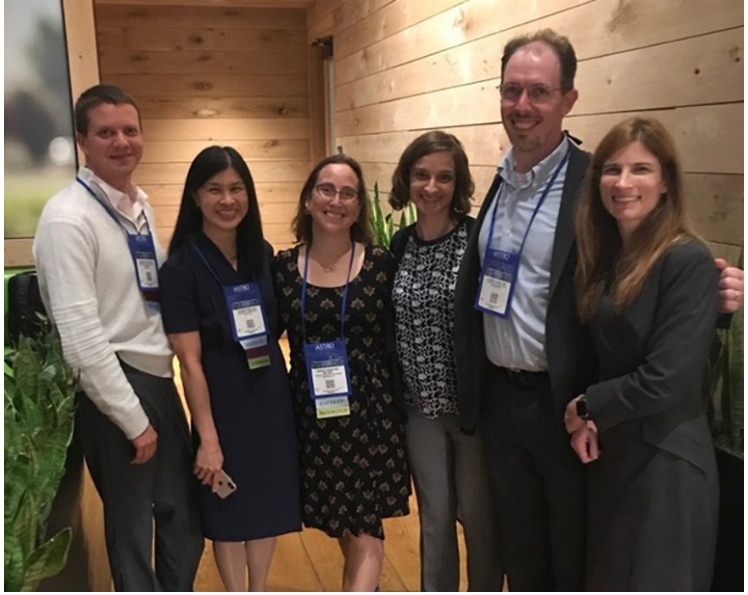

Figure 4 SPRO Executive committee: Dr. Timur Mitin, Dr. Yolanda Tseng, Dr. Candice Johnstone, Dr. Emily Martin, Dr. Joshua Jones, and Dr. Tracy Balboni. SPRO, Society for Palliative Radiation Oncology.

Society for Radiation Oncology (ASTRO) Guidelines Committee for both brain metastasis and bone metastasis, and he was a co-author on ASTRO Guidelines on palliative radiotherapy published in 2011 (bone), 2012 (brain), and 2016 (updated bone). He was Chair of the American College of Radiology (ACR) Expert Panel on Radiation OncologyBone Metastases and served as a panel member for the ACR Expert Panel on Radiation Oncology_Brain Metastases. He currently serves as Chair of the American Radium Society Appropriate Use Criteria Committee on Palliation and Symptom Management. Dr. Lo is also an expert in stereotactic body radiation therapy (SBRT) and formalized the spine SBRT program at the University of Washington. He has edited multiple textbooks on SBRT and stereotactic radiotherapy for brain, bone, and spine metastases. He has also co-authored consensus contouring guidelines for spine SBRT in the post-operative setting and for stereotactic radiosurgery to the resection cavity for brain metastases. Dr. Lo is committed to mentoring and educating junior faculty and residents and has notably been awarded Educator of the Year by both the University of Washington and the Association of Residents in Radiation Oncology.

Dr. Johnstone concluded the meeting by thanking all whose donations allowed complementary attendance to the SPRO Annual Meeting for medical students, residents, and fellows.

To learn more about SPRO or to join the mailing list, visit www.spro.org. 


\section{Acknowledgments}

Funding: None.

\section{Footnote}

Conflicts of Interest: All authors have completed the ICMJE uniform disclosure form (available at http://dx.doi. org/10.21037/apm-20-361). YT serves as an unpaid editorial board member of Annals of Palliative Medicine from May 2019 to Apr 2021. CBS 2nd serves as an unpaid Editors-in-Chief of Annals of Palliative Medicine. CJ serves as the Chair of Palliative Radiotherapy Subcommittee of Annals of Palliative Medicine from Jul 2019 to Jun 2021. EM has no conflicts of interest to declare.

Ethical Statement: The authors are accountable for all aspects of the work in ensuring that questions related to the accuracy or integrity of any part of the work are appropriately investigated and resolved.

Cite this article as: Martin E, Tseng Y, Simone CB 2nd, Johnstone C. Society for palliative radiation oncology: report from the Sixth Annual Meeting [2019]. Ann Palliat Med 2020;9(4):2420-2423. doi: 10.21037/apm-20-361
Open Access Statement: This is an Open Access article distributed in accordance with the Creative Commons Attribution-NonCommercial-NoDerivs 4.0 International License (CC BY-NC-ND 4.0), which permits the noncommercial replication and distribution of the article with the strict proviso that no changes or edits are made and the original work is properly cited (including links to both the formal publication through the relevant DOI and the license). See: https://creativecommons.org/licenses/by-nc-nd/4.0/.

\section{References}

1. Wei R, Simone CB 2nd, Lutz S. Society for palliative radiation oncology: founding, vision, and report from the Second Annual Meeting. Ann Palliat Med 2016;5:74-5.

2. Johnstone C, Martin E, Mitin T, et al. Society for Palliative Radiation Oncology: report from the Fifth Annual Meeting (2018). Ann Palliat Med 2019;8:S61-3.

3. Simone CB 2nd. Annals of Palliative Medicine earns its first official impact factor. Ann Palliat Med 2019;8:352-4. 